\title{
Health inequity in access to bariatric surgery: a protocol for a systematic review
}

Timothy D Jackson ${ }^{1 *}$, Rujun Zhang ${ }^{2}$, Dresden Glockler ${ }^{3}$, Jason Pennington ${ }^{4}$, Jacinta I Reddigan ${ }^{5}$, Ori D Rotstein ${ }^{5}$, Janet Smylie ${ }^{6}$, Laure Perrier ${ }^{7}$ and Lesley Gotlib Conn ${ }^{8}$

\begin{abstract}
Background: Bariatric surgery is the only weight-loss treatment available that results in both sustained weight loss and improvements of obesity-related comorbidities. Individuals who meet the eligibility criteria for bariatric surgery are generally older, come from racial or ethnic minorities, are economically disadvantaged, and have low levels of education. However, the population who actually receives bariatric surgery does not reflect the individuals who need it the most. The objective is to conduct a systematic review of the literature exploring the inequities to the access of bariatric surgery.
\end{abstract}

Methods/Design: EMBASE and Medline databases will be searched for observational studies that compared at least one of the PROGRESS-PLUS sociodemographic characteristics of patients eligible for bariatric surgery to those who actually received the procedure. Articles published in the year 1980 to present with no language restrictions will be included. For inclusion, studies must only include adults ( $\geq 18$ years old) who meet National Institutes of Health $(\mathrm{NIH})$ eligibility criteria for bariatric surgery defined as having either (1) a body mass index (BMI) of $40 \mathrm{~kg} / \mathrm{m}^{2}$ or greater; or (2) BMI of $35 \mathrm{~kg} / \mathrm{m}^{2}$ or greater with significant weight-related comorbidities. Eligible interventions will include malabsorptive, restrictive, and mixed bariatric procedures.

Discussion: There appears to be inequities in access to bariatric surgery. In order to resolve the health inequity in the treatment of obesity, a synthesis of the literature is needed to explore and identify barriers to accessing bariatric surgery. It is anticipated that the results from this systematic review will have important implications for advancing solutions to minimize inequities in the utilization of bariatric surgery.

http://www.crd.york.ac.uk/PROSPERO/display_record.asp?ID=CRD42013004920.

Keywords: Bariatric surgery, Sociodemographic disparities, Obesity, Systematic review

\section{Background}

Obesity is the leading cause of preventable death in the developed world [1,2]. Since the 1970's, the prevalence of obesity has increased dramatically. Recent estimates indicate that $24 \%$ of Canadian adults and $34 \%$ of American adults are obese, defined as having a Body Mass Index $(\mathrm{BMI}) \geq 30 \mathrm{~kg} / \mathrm{m}^{2}$ [3]. The prevalence of morbid obesity, defined as having a BMI $\geq 40 \mathrm{~kg} / \mathrm{m}^{2}$, has increased by $400 \%$ in the past two decades $[4,5]$. The reduced quality of life and the life expectancy associated with obesity due to obesity-related comorbidities [6,7], such as diabetes and hypertension, are even more pronounced

\footnotetext{
*Correspondence: Timothy.Jackson@uhn.ca

'Division of General Surgery, University Health Network, 399 Bathurst Street, Toronto, ON M5T 2S8, Canada

Full list of author information is available at the end of the article
}

among those who are classified as morbidly obese [8]. The current obesity epidemic reflects the limited benefits of medically supervised weight-loss interventions to sustain weight loss $[9,10]$.

Bariatric surgery has been documented as being the only treatment available that results in sustained weight loss, leading to significant improvement in obesity-related comorbidities [11]. Indeed, bariatric surgical procedures significantly decrease overall mortality in those patients who received such procedures compared to controls [12]. The current indications for bariatric surgery as determined by the National Institutes of Health (NIH) criteria [13] include patients with a BMI of $40 \mathrm{~kg} / \mathrm{m}^{2}$ or greater, or a BMI of $35 \mathrm{~kg} / \mathrm{m}^{2}$ or greater with significant weight-related comorbidities. When bariatric surgery is delivered in the appropriate model of care, these procedures are associated 
with low morbidity and mortality [14-17] and have been proven to be cost effective [18-20].

Despite the evidence supporting the safety, clinical benefits and cost effectiveness of bariatric surgery, uptake of these procedures in eligible patients remains low [21]. Health inequity, defined as unfair inequalities in population groups that lead to unequal chances to access health care services [22], may be to blame. Studies have documented significant disparities between the general morbidly obese population and the subset that have access to and/or receive bariatric surgical procedures [23-25]. Compared to the general population, individuals who fulfill the NIH criteria, and therefore are candidates for bariatric surgery, are often older, come from racial or ethnic minorities, are economically disadvantaged, and have low levels of education $[23,26]$. However, it is this subset of the population that is least likely to have access to bariatric surgery [25].

In an effort to create equity in the access to bariatric surgery for the treatment of obesity, a clear understanding of the apparent disparities is required. The acronym PROGRESS-Plus describes the sociodemographic factors across which disadvantage may exist: Place of residence; Race/ethnicity/culture; Occupation; Gender/sex; Religion; Education; Socioeconomic status; Social capital; Plus additional factors (for example, age) [27,28]. This protocol describes a systematic review that aims to identify the PROGRESS-Plus factors that differ between morbidly obese patients who are eligible for weight reduction surgery and those who actually receive this operation.

\section{Methods}

Eligibility

\section{Types of studies}

Retrospective and prospective cohort studies, case series, case control, and cross-sectional survey studies will be included, irrespective of the blinding employed (for example, single-blinded or open). To be included, studies must compare study participants on at least one of the PROGRESS-Plus factors.

\section{Types of participants}

Adult patients over the age of 18 meeting the NIH criteria for bariatric surgery will be included, irrespective of geographical location. The NIH criteria for bariatric surgery include having: (1) a BMI $\geq 40 \mathrm{~kg} / \mathrm{m}^{2}$ or (2) a BMI $\geq 35 \mathrm{~kg} / \mathrm{m}^{2}$ with at least one significant weight-related comorbidity [13].

\section{Types of intervention}

The intervention must be a bariatric surgery that may include the following procedure types: Roux-en-Y gastric bypass, sleeve gastrectomy, adjustable gastric band, vertical banded gastroplasty, jejunoileal bypass, biliopancreatic diversion, duodenal switch, mini-gastric bypass, loop gastric bypass, gastric placation, gastric balloon, or scopinaro procedure. Both open and laparoscopic approaches will be considered.

Interventions may be either universally implemented or targeted to a specific risk group. The control group must be assigned to receive no intervention, standard care or assigned to a wait-list group.

\section{Outcome}

\section{Main outcome}

The outcome of interest is the utilization of bariatric surgery. Two groups have been a priori defined as (1) patients who are eligible for bariatric surgery and receive the procedure, and (2) those who are eligible for bariatric surgery but do not receive the procedure.

\section{Sociodemographic factors}

The PROGRESS-PLUS sociodemographic factors will be used to explore the factors associated with bariatric surgery delivery. Place of residence will be categorized by the geographical location of residence classified as urban, suburban and rural. Race/ethnicity/culture will be defined by ethnicity with the following categories: British; Eastern European, Western European, Asian, South Asian, Black, Hispanic, Aboriginal, and Other. Occupation will be categorized as being professional, skilled, unskilled and unemployed. Gender/sex will be categorized as being male or female. Religion will be categorized as identifying with Christianity/Catholicism, Judaism, Islam and Other. Education will be categorized by the highest level of education attained (graduate; post-secondary, secondary and primary). Socioeconomic status will be documented as median and interquartile range (IQR) household income and will be categorized into the following income categories: < $\$ 50,000$, between 50,000 and $\$ 99,000$, or $\geq \$ 100,000$. Social capital will be defined by family support as being full support, some support or no support. Plus factors will include age and health insurance. Age will be documented as mean interquartile range and categorized into the following age categories: 18 to 19 years, 20 to 39 years, 40 to 59 years, and $60+$ years. Health insurance will be defined by the type of insurance, classified as being universal, private or none.

\section{Search strategy}

Studies will be indentified through the bibliographic databases of EMBASE, Medline (See Appendix 1 in Additional file 1), and hand searching of journals, meeting abstracts, technical or research reports, monographs, doctoral dissertations, bibliographies of retrieved papers, and relevant web sites. In addition, unpublished studies and gray literature will be sought through internet searches with specific websites targeted, including: 
1. Statistics Canada: http://www.statcan.gc.ca/startdebut-eng.html

2. Royal College of Physicians and Surgeons of Canada: http://www.royalcollege.ca/

3. Institute for Clinical Evaluative Sciences: http:// www.ices.on.ca/index.html

4. Canadian Institute for Health Information: http://www.cihi.ca

5. American College of Surgeons: http://www.facs.org/

6. National Centre for Health Statistics: http://www. cdc.gov/nchs/

7. National Institutes of Health: http://www.nih.gov/

8. Agency for Healthcare Research and Quality: http:// www.ahrq.gov/

9. Royal College of Surgeons of England: http://www. rcseng.ac.uk/

10.Health and Social Care Information Centre: http:// www.hscic.gov.uk/

11.European Institute for Health Records: http://www. eurorec.org/

12.Royal Australasian College of Surgeons: http://www. surgeons.org/

13.Australian Institute for Health and Welfare: http:// www.aihw.gov.au/

The search strategies will be developed by an experienced librarian and peer reviewed using Peer Review of Electronic Search Strategy (PRESS) [29]. The final search strategy will combine medical subject headings $(\mathrm{MeSH}$ terms) and appropriate wildcards. No publication language limit will be set during the database searches. A lower date limit of 1980 will be set as the availability of bariatric surgery prior to 1980 was not widespread.

\section{Study selection}

Two research assistants will review the title, abstraction or description of all trials identified by the literature search. Those studies that aim to explore bariatric surgery among individuals over the age of 18 will be selected for full-text review to determine if they meet inclusion criteria. Any discrepancy will be resolved by a third person.

\section{Data extraction}

Two researchers will independently extract data from included studies on a prepared data collection form. The data abstraction form will be pilot tested on a random sample of studies to ensure high inter-rater agreement between reviewers. Extracted data will include: study characteristics; primary outcome results; patient risk factors, including BMI, smoking status, mental health status, quality of life, and physical activity level; and details of the surgical intervention. The presence or absence of the following comorbidities will be documented: hypertension, dyslipidemia, diabetes, coronary artery disease, cerebrovascular disease, depression, hypothyroidism, sleep apnea, gastroesophageal reflux, osteoarthrisits, and cholelithiasis.

\section{Quality assessment}

Two researchers will independently assess the quality of all studies included for review. Any discrepancy will be resolved by a third reviewer. To quantify the degree of bias in the included studies, the Newcastle-Ottawa Scale (NOS) will be used [30]. The NOS was developed for quality assessment of observational epidemiological studies (http://www.ohri.ca/programs/clinical_epidemiology/ oxford.asp). The NOS has three categories within which risk of study bias can be determined: selection, comparability and outcome. In assessing risk of bias in cohort studies, the NOS awards a ranking for the selection of the cohort, comparability of the cohort and for the assessment of outcomes. In assessing risk of bias in case-control studies, the NOS awards a ranking for the selection of cases and controls, in the comparability of cases and controls and for the ascertainment of the exposure.

\section{Data synthesis and analysis}

Health inequities in accessing bariatric surgery will be explored using two of the following methods: first, data permitting, metaregression via a multivariate logistic regression using study-level data will be used to explore the PROGRESS-PLUS factors associated with the utilization of bariatric surgery (yes/no). This analysis will allow for the assessment of the impact of any individual covariates on utilization rates, as well as of a potential effect modifier. In addition, differences in PROGRESS-PLUS factors between the surgery and no surgery group within individual studies will be explored. The proportion of study participants categorized within each PROGRESS-PLUS category will be summarized as a percentage with a corresponding $95 \%$ confidence interval (CI) for dichotomous and categorical variables, and as median and interquartile range (IQR) for continuous variables. Second, differences in PROGRESSPLUS factors between groups will be compared using $x^{2}$ test or Fisher's exact test for categorical variables and the Wilcoxon-Mann-Whitney test for continuous variables. Statistical tests will be carried out as 2-tailed tests at $\alpha=0.05$. The DerSimonian and Laird method will be used to test heterogeneity of effect sizes between studies. Heterogeneity will be assumed at $P<0.05$ and $\mathrm{I}^{2} \geq 25 \%$. Data will be analyzed with SAS (version 9.1; SAS Institute Inc. Cary, NC, USA).

Irrespective of the presence or absence of heterogeneity the following subgroup analyses on the main outcome will be performed to explore possible effect modifications:

\section{Participants characteristics}


2. Intervention type; and

3. Study quality

\section{Discussion}

While bariatric surgery has been demonstrated to be an effective treatment for obesity, it appears that access to, and uptake of bariatric surgery does not uniformly match with populations with high rates of obesity and obesity-related diseases [23-25]. Factors such as ethnicity, age, sex, socioeconomic status, geographic location and others appear to play an important role in determining access to care. In order to address barriers and move toward health equity in the treatment of obesity, a synthesis of the literature is needed to fully explore and identify the gaps in our understanding of access to bariatric surgery. We will disseminate the results of this review in an open access scientific journal and will present results at scientific conferences. We expect our results will have important implications for the delivery of bariatric surgery by providing some leads to the barriers to accessing these operations. Findings of inequities in the access to bariatric surgery will be used to inform the design of qualitative research which will provide insight into what drives the identified factors to act as barriers and help prioritize solutions to bridge the care gap.

\section{Additional file}

Additional file 1: Appendix I. Literature Search Strategy.

\section{Abbreviations}

BMI: body mass index; NIH: National Institutes of Health; MeSH: Medical Subject Headings; NOS: Newcastle-Ottawa Scale.

\section{Competing interests}

The authors declare that they have no competing interests.

\section{Authors' contributions}

TJ collaborated in the design of the study and drafted the protocol. ODR conceived the study, collaborated in the design of the study, and edited the protocol. RZ collaborated in the design of the study and edited the protocol. DG collaborated in the design of the study and edited the protocol. JP collaborated in the design of the study and edited the protocol. JIR collaborated in the design of the study and edited the protocol. JS collaborated in the design of the study and edited the protocol. LP developed the search strategy and edited the protocol. LGC collaborated in the design of the study and edited the protocol. All authors read and approved the final manuscript.

\section{Acknowledgements}

Special acknowledgement to Sanjit Bhogal who critically reviewed and revised the protocol for important methodological content. This systematic review is funded by the Department of Surgery, St. Michael's Hospital.

\section{Author details}

'Division of General Surgery, University Health Network, 399 Bathurst Street, Toronto, ON M5T 2S8, Canada. ${ }^{2}$ University of Ottawa, 75 Laurier Avenue East, Ottawa, ON K1N 6 N5, Canada. ${ }^{3}$ University of Western Ontario, 1151 Richmond St, London, ON N6A 3 K7, Canada. ${ }^{4}$ Division of General Surgery, The Scarborough Hospital, 3050 Lawrence Avenue East, Scarborough, ON M1P 2 V5, Canada. ${ }^{5}$ Department of Surgery, St. Michael's Hospital, 30 Bond
Street, Toronto, ON M5B 1 W8, Canada. ${ }^{6}$ Centre for Research on Inner City Health, Keenan Research Centre of the Li Ka Shing Knowledge Institute, St. Michael's Hospital, 30 Bond Street, Toronto, ON M5B 1 W8, Canada. 'Knowledge Translation Program, Li Ka Shing Knowledge Institute, St. Michael's Hospital, 30 Bond Street, Toronto, ON M5B 1 W8, Canada. ${ }^{8}$ Sunnybrook Research Institute, 2075 Bayview Avenue, K3W-27, Toronto, ON M4N 3 M5, Canada.

Received: 4 November 2013 Accepted: 3 February 2014

Published: 21 February 2014

\section{References}

1. Stewart ST, Cutler DM, Rosen AB: Forecasting the effects of obesity and smoking on U.S. life expectancy. N Engl J Med 2009, 361:2252-2260.

2. World Health Organization: Obesity: preventing and managing the global epidemic. Report of a WHO consultation. World Health Organ Tech Rep Ser 2000, 894:1-253.

3. McGuire S, Shields M, Carroll MD, Ogden CL: Adult obesity prevalence in Canada and the United States. NCHS data brief no. 56, Hyattsville, MD: National Center for Health Statistics, 2011. Adv Nutr 2011, 2:368-369.

4. Katzmarzyk PT, Mason C: Prevalence of class I, II and III obesity in Canada. CMAJ 2006, 174:156-157.

5. Sturm R, Hattori A: Morbid obesity rates continue to rise rapidly in the United States. Int J Obes (Lond) 2013, 37:889-891.

6. Fontaine KR, Redden DT, Wang C, Westfall AO, Allison DB: Years of life lost due to obesity. JAMA 2003, 289:187-193.

7. Chang SH, Pollack LM, Colditz GA: Life years lost associated with obesityrelated diseases for U.S. non-smoking adults. PLoS One 2013, 8:e66550.

8. Lau DC, Douketis JD, Morrison KM, Hramiak IM, Sharma AM, Ur E: Canadian clinical practice guidelines on the management and prevention of obesity in adults and children [summary]. CMAJ 2006, 176:S1-S13.

9. Appel L, Clark JM, Yeh HC, Wang NY, Coughlin JW, Daumit G, Miller ER 3rd, Calcin A, Jerone GJ, Geller S, Noronha G, Pozefsky T: Comparative effectiveness of weight-loss interventions in clinical practice. $N$ Engl J Med 2011, 365:1959-1968.

10. Wadden TA, Volger S, Sarwer DB, Vetter ML, Tsai AG, Berkowitz RI, Kumanuika S, Schmitz KH, Diewalk LK, Barg R, Chittams J, Moore RH: A two-year randomized trial of obesity treatment in primary care practice. N Engl J Med 2011, 365:1969-1979.

11. Buchwald H, Avidor Y, Braunwald E, Jensen MD, Pories W, Fahrbach $K$, Schoelles K: Bariatric surgery: a systematic review and meta-analysis. JAMA 2004, 292:1724-1737.

12. Sjostrom L, Narbro K, Sjostrom CD, Karason K, Larsson B, Wedel H, Lystig T, Sullivan M, Bouchard C, Carlsson B, Bengtsson C, Dahlgren S, Gummesson A, Jacobson P, Karlsson J, Lindroos AK, Lönroth H, Näslund I, Olbers T, Stenlöf K, Torgerson J, Agren G, Carlsson LM, Swedish Obese Subjects Study: Effects of bariatric surgery on mortality in Swedish obese subjects. N Engl I Med 2007, 357:741-752.

13. $\mathrm{NIH}$ conference: Gastrointestinal surgery for severe obesity. Consensus development conference panel. Ann Intern Med 1991, 115:956-961.

14. Longitudinal Assessment of Bariatric Surgery (LABS) Consortium, Flum DR, Belle SH, King WC, Wahed AS, Berk P, Chapman W, Pories W, Courcoulas A, McCloskey C, Mitchell J, Patterson E, Pomp A, Staten MA, Yanovski SZ, Thrilby R, Wolfe B: Perioperative safety in the longitudinal assessment of bariatric surgery. N Engl J Med 2009, 361:445-454.

15. Hutter MM, Schirmer BD, Jones DB, Ko CY, Cohen ME, Merkow RP, Nquyen NT: First report from the American College of Surgeons Bariatric Surgery Center Network: laparoscopic sleeve gastrectomy has morbidity and effectiveness positioned between the band and the bypass. Ann Surg 2011, 254:410-420.

16. Finks JF, Kole KL, Yenumula PR, English WJ, Krause KR, Carlin AM, Genaw JA, Banerjee M, Birkmever JD, Birkmeye NJ, Michigan Bariatric Surgery Collaborative, from the Centre for Healthcare Outcomes and Policy: Predicting risk for serious complications with bariatric surgery: results from the Michigan Bariatric Surgery Collaborative. Ann Surg 2011, 254:633-640.

17. Encinosa WE, Bernard DM, Du D, Steiner CA: Recent improvements in bariatric surgery outcomes. Med Care 2009, 47:531-535.

18. Picot J, Jones J, Colquitt JL, Gospodarevskaya E, Loveman E, Baxter L, Clegg AJ: The clinical effectiveness and cost-effectiveness of bariatric (weight loss) surgery for obesity: a systematic review and economic evaluation. Health Technol Assess 2009, 13:1-357. iii. 
19. Cremieux PY, Ghosh A, Yang HE, Buessing M, Buchwald H, Shikora SA: Return on investment for bariatric surgery. Am J Manag Care 2008, 14:e5-e6.

20. Sampalis JS, Liberman M, Auger S, Christou NV: The impact of weight reduction surgery on health-care costs in morbidly obese patients. Obes Surg 2004, 14:939-947.

21. Flum DR, Khan TV, Dellinger EP: Toward the rational and equitable use of bariatric surgery. JAMA 2007, 298:1442-1444.

22. Whitehead M: The concepts and principles of equity and health. Int $J$ Health Serv 1992, 22:429-445.

23. Martin M, Beekley A, Kjorstad R, Sebesta J: Socioeconomic disparities in eligibility and access to bariatric surgery: a national population-based analysis. Surg Obes Relat Dis 2010, 6:8-15.

24. Santry HP, Gillen DL, Lauderdale DS: Trends in bariatric surgical procedures. JAMA 2005, 294:1909-1917.

25. Wallace AE, Young-Xu Y, Hartley D, Weeks WB: Racial, socioeconomic, and rural-urban disparities in obesity-related bariatric surgery. Obes Surg 2010, 20:1354-1360.

26. Padwal RS, Chang HJ, Klarenbach S, Sharma AM, Majumdar SR: Characteristics of the population eligible for and receiving publicly funded bariatric surgery in Canada. Int J Equity Health 2012, 11:54.

27. Evans T, Brown $\mathrm{H}$ : Road traffic crashes: operationalizing equity in the context of health sector reform. Inj Control Saf Promot 2003, 10:11-12.

28. Oliver S, Kavanagh J, Caird J, Lorenc T, Oliver K, Harden A, Thomas J, Greaves A, Oakley A: Health Promotion, Inequalities and Young People's Health. A Systematic Review of Research. London: EPPI-Centre, Social Science Research Unit, Institute of Education, Univeristy of London [http://eppi.ioe. ac.uk/cms/Default.aspx? tabid $=2410]$

29. Sampson M, McGowan J, Cogo E, Grimshaw J, Moher D, Lefebvre C: An evidence-based practice guideline for the peer review of electronic search strategies. J Clin Epidemiol 2009, 62:944-952.

30. Wells G, Shea B, O'Connell D, Peterson J, Welch V, Losos M, Tugwell P: The Newcastle-Ottawa Scale (NOS) for assessing the quality of nonrandomised studies in meta-analyses. [http://www.ohri.ca/programs/ clinical_epidemiology/oxford.asp]

doi:10.1186/2046-4053-3-15

Cite this article as: Jackson et al.: Health inequity in access to bariatric surgery: a protocol for a systematic review. Systematic Reviews 2014 3:15.

\section{Submit your next manuscript to BioMed Central and take full advantage of:}

- Convenient online submission

- Thorough peer review

- No space constraints or color figure charges

- Immediate publication on acceptance

- Inclusion in PubMed, CAS, Scopus and Google Scholar

- Research which is freely available for redistribution 